\title{
Video assisted laser resection of lung metastases: a new surgical technique
}

\author{
Andreas Kirschbaum ${ }^{1}$, Christian Meyer ${ }^{1}$, Detlef Bartsch $^{1}$, Nikolas Mirow ${ }^{2}$ \\ ${ }^{1}$ Department of Surgery, University Hospital Marburg, Marburg, Germany; ${ }^{2}$ Department of Cardiac Surgery, University Hospital Marburg, \\ Marburg, Germany \\ Correspondence to: Prof. Dr. Andreas Kirschbaum. Department of Surgery, University Hospital Marburg, Baldingerstrasse, D-35035 Marburg, \\ Germany. Email: Kirschbaum001@gmx.de.
}

\begin{abstract}
Lung metastases may be found in almost every kind of malignant tumor. If appropriate, surgical removal should be considered. The goal of surgery is complete removal of all existing lung metastases. Frequently open access is favored in order to inspect all parts of the affected lung and detected metastases are preferably removed non-anatomically applying a Nd:YAG laser. The innovative surgical technique described here allows for palpation of the entire lung via a minithoracotomy and facilitates video-assisted removal of all lung metastases. Thus the benefits of minimally invasive surgery can be harnessed for the patients at the same time offering radical tumor removal. It may be estimated that the technique described will become the future standard procedure for surgery of lung metastases.
\end{abstract}

Keywords: Lung metastasis; videothoracoscopy; laser; laser fiber; thoracic surgery; video-assisted surgery

Received: 30 November 2019; Accepted: 13 January 2020; Published: 25 May 2020.

doi: $10.21037 /$ ccts.2020.01.03

View this article at: http://dx.doi.org/10.21037/ccts.2020.01.03

\section{Introduction}

From a surgical point of view the aim of treating of lung metastases is complete removal of all detectable lung tumors. Non-anatomical resection procedures i.e., clamp resection, stapler or laser, are considered standard. Generally all lung metastases should be excised at a distance of $1 \mathrm{~cm}$ from the surrounding healthy lung parenchyma (1). If this is not possible due to the tumor's anatomical position, anatomical resection (segment, flap) is performed.

Through the mid-90's, lung metastasis removal was usually performed with open access. In some departments, sternotomy was performed to remove lung metastases on both sides in one session (2-4). In 1993, Dowling RD et al. published a study of 63 patients with peripheral lung metastases removed by stapler using video-assistance. The method's technical feasibility was evident (5). De Giacomo et al. (6) compared long-term results of video-assisted resections with those of open surgery and were able to demonstrate very similar long-term survival rates. In a review of current lung metastasis surgery in 2008 Treasure (7) wrote, that in nearly $20 \%$ of cases intraoperative palpation revealed more foci than imaging had suggested. In his opinion video assisted resection should only be performed in cases of solitary pulmonary lesions. In addition, he found that central foci were difficult to palpate during video thoracoscopy. In the same year, a survey was carried out among European thoracic surgeons (8). A total of $65.1 \%$ of the surgeons considered a thoracotomy with palpation of the entire lung to be mandatory. And $60.3 \%$ of the respondents judged video thoracoscopy a pure diagnostic tool to further examine pulmonary nodules. At the time only a small proportion of surgeons were prepared to employ the technique with a curative objective. One year later, Carballo et al. (9) summarized the previously recommended criteria for video assisted removal of lung metastases: small foci with a size less than two $\mathrm{cm}$, less than two in number, one-sided peripheral location. Pfannschmidt et al. (10) was sceptical about the risk of port canal metastases, difficult mediastinal lymphadenectomy and insufficient safety clearance from the staple line. In 2012, Chao et al. (11) published a randomized study comparing open surgery to video thoracoscopy 
(VATS). He was able to show that the VATS group suffered from significantly less postoperative pain, had shorter in hospital treatment and a better compliance with regard to adjuvant treatment. These observations were later confirmed by other authors $(12,13)$.

In this context, Abdelnour-Berchtold (14) investigated the significance of performing high resonance computed tomography (HR-CT) in preparation for lung metastasis resection. At 120 months after resection only $10 \%$ of the video-assisted patients exhibited new ipsilateral pulmonary metastases. Presently Greater et al. (15) considers videoassisted techniques feasible in defined constellations regarding location and number of metastases detected.

In our opinion, there are two major problems with the video-assisted approach. First: standard trocar access allows for only limited instrumental palpation of the affected lung. Second: the use of stapling devices leads to the sacrifice of healthy lung tissue, especially so, if central portions of the lung are affected. Video-assisted lobectomy has been part of the surgical repertoire for several years though. Usually a mini-thoracotomy is carried out in the 4th intercostal space and a lightweight self-retaining retractor is positioned. This technique can be applied to the surgery of metastases too, as by inserting two fingers the entire lung can be thoroughly palpated. Laser is an important contribution to the strategy. In open surgery in order to dispense with the use of staplers, Nd:YAG lasers (wavelength: 1,318 nm) connected to a focusing handpiece have been used for many years. Healthy parenchyma is saved to a considerable extent and with little bleeding (16). Superficial resections are airtight and no longer need additional suturing. Even more centrally located lung metastases can be removed with precision, omitting the need for anatomical resection. Video-assisted resection via mini-thoracotomy using a focusing handpiece of the kind employed in open surgery is feasible, as we were able to demonstrate in a small study (17). For this less invasive application however, these commercially available handpieces are frequently too short and correct alignment with the lung parenchyma inside the thoracic cavity may be difficult. For this reason we are currently using thinner and longer laser fibers. We will describe this new surgical technique in more detail.

\section{Patient selection, indication}

In order to qualify for lung interventions, patients must have appropriate cardiopulmonary reserves. A current thoracic CT-scan should be available for evaluation. If the lung metastases detected are situated more centrally, bronchoscopy is performed to check for possible bronchial infiltration. All endoscopically visible tumors are anatomically removed as a segment or a flap employing video-assistance. Complete resection is mandatory. In addition to this essential point, generally accepted criteria for lung metastasis surgery (no distant metastases, sufficient treatment of the primary tumor, exclusion of recurrence, and no mediastinal lymph node metastases) should be given (18). In our practice an institutional tumor board has issued appropriate recommendations.

\section{Surgical technique}

A double-tube is placed and the patient is adequately positioned. Under sterile conditions an anterolateral minithoracotomy (length: $4 \mathrm{~cm}$ ) is performed at the level of the 4th ICS. A self-retaining retractor (Applied Medical GmbH, Dusseldorf, Germany) is applied (see Figure 1). The access should permit two fingers to be inserted. A thoracoscope (30 degree optic) is inserted through this port. Diagnostic thoracoscopy is performed. Either one or two additional trocars are inserted superior to the diaphragm under visual control. The lower lobe is lifted with a forceps and electrocautery is used to sever the ligamentum pulmonale. The lungs can now be mobilized cranially. Following this the entire lung is thoroughly palpated between two inserted fingers (see Figure 2). After identification of a pulmonary metastasis, it is resected non-anatomically using a laser fiber $(800 \mu \mathrm{m}$, KLS Martin, Gebrüder Martin \& CoKG, Tuttlingen, Germany) (see Figure 3). The fiber is introduced and maneuvered via a specific holder. It is connected to a Nd:YAG laser (wavelength $1,318 \mathrm{~nm}$, power 60 watts, LIMAX ${ }^{\circledast} 120$, KLS Martin, Gebrüder Martin $\mathrm{GmbH} \& \mathrm{Co} \mathrm{KG}$ ). Resected specimen is removed via the minithoracotomy. Via the laser fiber additional coagulation of superficial pulmonary resection surfaces can be achieved (Figure 4). Deeper parenchymal lesions of more than $2 \mathrm{~cm}$ are closed by surgical sutures under endoscopic view using PDS 4-0 (Johnson \& Johnson Medical GmbH, Norderstedt, Germany). Lymphadenectomy is performed in analogy to video-assisted segmental or flap resections. At the end of the operation, we thoroughly rinse the chest cavity and ventilate the lungs. Persisting larger parenchymal air leaks are closed by further suturing. A single chest drainage ( $\mathrm{CH} \mathrm{24)} \mathrm{is} \mathrm{inserted} \mathrm{under} \mathrm{videothoracoscopic}$ view. The minithoracotomy is closed and the skin is sutured intracutaneously with a resorbable suture. 


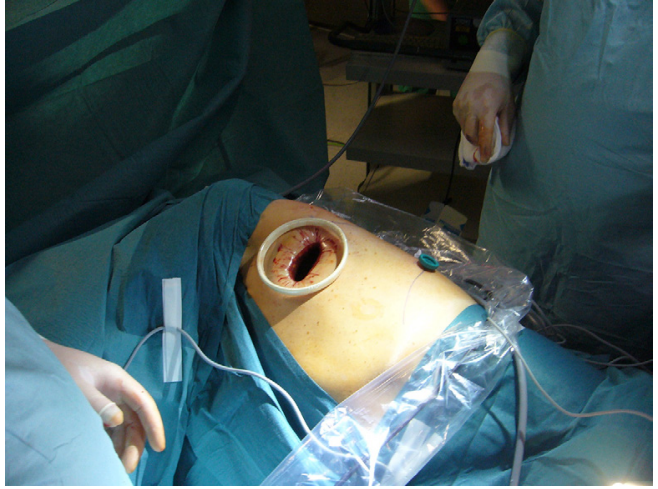

Figure 1 View of the mini-thoracotomy with inserted selfretaining retractor.

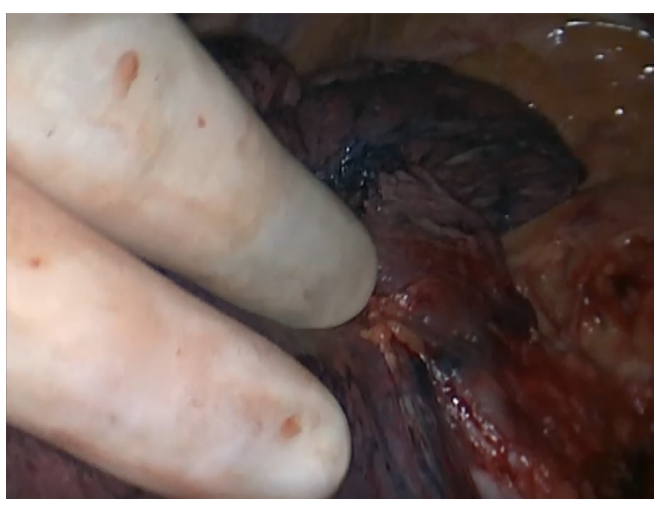

Figure 2 Fingers inserted into the thoracic cavity for palpation of the lung.

\section{Postoperative treatment}

Suction of $-10 \mathrm{cmH}_{2} \mathrm{O}$ is applied to the inserted chest tube. A thoracic X-ray in one plane is taken on the day of the operation. With no evidence of parenchymal fistulation, the suction is removed from the chest tube on the first postoperative day. If the secretion remains below $200 \mathrm{~mL} /$ day, the chest tube can be removed. On average, on the 4th postoperative day, patients may be discharged from inpatient treatment. Ten days after extracting the chest drainage, the suture closing the insertion site can be removed.

\section{Ethics and consent}

All procedures performed in this study were in accordance with the ethical standards of the institutional and national research committees and with the Helsinki Declaration (as revised in 2013). Written informed consent was obtained

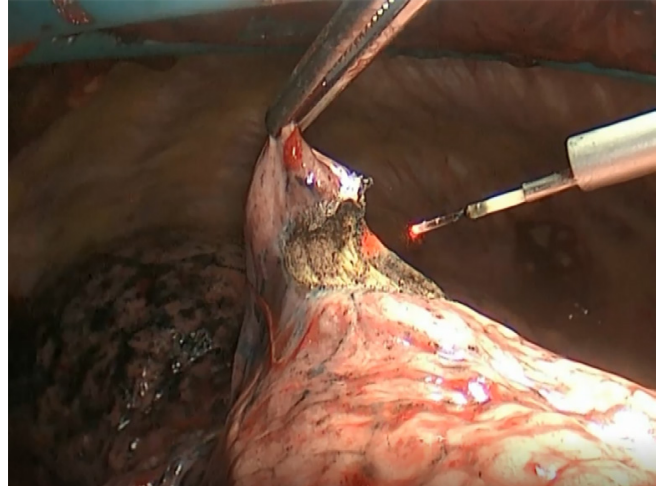

Figure 3 Videothoracoscopic view of the laser fiber in use to remove a lung metastasis.

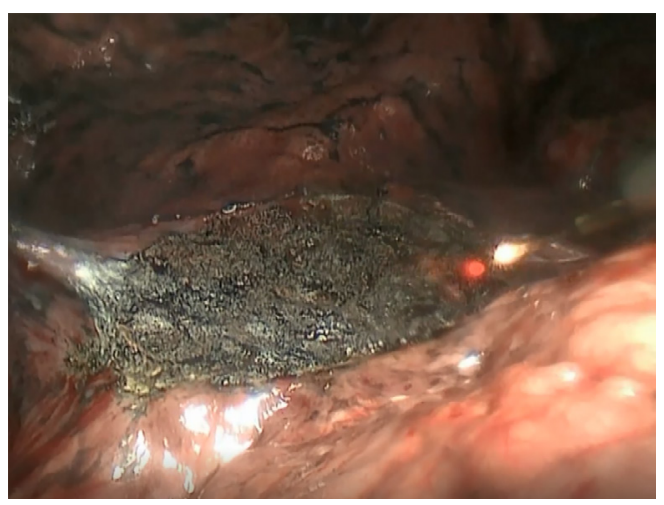

Figure 4 The resection surface is coagulated again by the laser fiber in order to improve air tightness.

from the patient for publication of this manuscript and any accompanying images. A copy of the written consent is available for review by the editorial office of this journal.

\section{Comments}

The mini-thoracotomy should be large enough to be able to comfortably insert two fingers into the thoracic cavity. Palpation of the lung should be performed systematically as in open surgery. Once a lung metastasis has been palpated, it may be marked and exposed with a suture. Resection of each tumor should commence below this marking suture. It is important to optimize a smoke evacuation system, which is essential for a clear view of the surgical field. This feature is integrated in the fiber holder we use. In case of very dense smoke inside the thoracic cavity, a standard OR suction device is additionally introduced via the minithoracotomy. 
The quality of the fiber tip must be checked regularly in order for the laser to deliver its full power. If the fiber starts burning, it must be removed from the site and reprocessed. For parenchyma resections with a depth of more than $2 \mathrm{~cm}$, the resection surface should be examined for potentially opened segmental bronchi. Moderate ventilation of this area can unmask leaking bronchi. In our experience they require additional suturing for proper closure. Furthermore these parenchymal areas should be closed systematically by over-sutures in several layers. If the laser is used in more central areas of the lung, its power should be reduced to avoid injury to vessels and bronchi. In the event bleeding in this area, as a first step the tissue is compressed with a swab for a few minutes. Only then should the situation be re-evaluated. Injured vessels with minor injuries can be closed by either an endoscopic suture or by a clip. In case of uncontrollable bleeding, the existing mini-thoracotomy can easily be enlarged for open access.

\section{Summary}

Surgery of lung metastases requires all existing pulmonary foci to be removed as completely but also sparingly as healthy parenchyma is concerned. At the same time the procedural risk should be low. The technique of videoassisted laser resection described here meets all requirements listed. It combines the advantages of minimally invasive procedures with the necessary oncological radicality. It may be expected to become the future standard procedure in surgery of lung metastases.

\section{Acknowledgments}

Funding: None.

\section{Footnote}

Provenance and Peer Review: This article was commissioned by the Guest Editors (Francesco Zaraca, Reinhold Perkmann, Luca Bertolaccini and Roberto Crisci) for the series "Thoracic Surgery Without Borders" published in Current Challenges in Thoracic Surgery. The article has undergone external peer review.

Conflicts of Interest: All authors have completed the ICMJE uniform disclosure form (available at https://ccts. amegroups.com/article/view/10.21037/ccts.2020.01.03/ coif). The series "Thoracic Surgery Without Borders" was commissioned by the editorial office without any funding or sponsorship. The authors have no other conflicts of interest to declare.

Ethical Statement: The authors are accountable for all aspects of the work in ensuring that questions related to the accuracy or integrity of any part of the work are appropriately investigated and resolved. All procedures performed in this study were in accordance with the ethical standards of the institutional and national research committees and with the Helsinki Declaration (as revised in 2013). Written informed consent was obtained from the patient for publication of this manuscript and any accompanying images. A copy of the written consent is available for review by the editorial office of this journal.

Open Access Statement: This is an Open Access article distributed in accordance with the Creative Commons Attribution-NonCommercial-NoDerivs 4.0 International License (CC BY-NC-ND 4.0), which permits the noncommercial replication and distribution of the article with the strict proviso that no changes or edits are made and the original work is properly cited (including links to both the formal publication through the relevant DOI and the license). See: https://creativecommons.org/licenses/by-nc-nd/4.0/.

\section{References}

1. Rusch VW. Pulmonary metastasectomy. Current indications. Chest 1995;107:322S-331S.

2. Rendina EA, Mineo TC, Facciolo F, et al. Median sternotomy for resection of lung metastases. Ital J Surg Sci 1985;15:375-9.

3. Swoboda L, Toomes H. Median sternotomy as an approach to surgery of lung metastases. Helv Chir Acta 1987;53:531-5.

4. Swoboda L, Toomes H. Results of surgical treatment for pulmonary metastases. Thorac Cardiovasc Surg 1986;34 Spec No 2:149-52.

5. Dowling RD, Keenan RJ, Ferson P, et al. Video-assisted thoracoscopic resection of pulmonary metastases. Ann Thorac Surg 1993;56:772-5.

6. De Giacomo T, Rendina EA, Venuta F, et al. Thoracoscopic resection of solitary lung metastases from colorectal cancer is a viable therapeutic option. Chest $1999 ; 115: 1441-3$.

7. Treasure T, Internullo E, Utley M. Resection of pulmonary metastases: a growth industry. Cancer Imaging 
2008;8:121-4.

8. Internullo E, Cassivi SD, Van Raemdonck D, et al. Pulmonary metastasectomy: a survey of current practice amongst members of the European Society of Thoracic Surgeons. J Thorac Oncol 2008;3:1257-66.

9. Carballo M, Maish MS, Jaroszewski DE, et al. Video-assisted thoracic surgery (VATS) as a safe alternative for the resection of pulmonary metastases: a retrospective cohort study. J Cardiothorac Surg 2009;4:13.

10. Pfannschmidt J, Dienemann H. Current surgical management of pulmonary metastases. Zentralbl Chir 2009;134:418-24.

11. Chao YK, Chang HC, Wu YC, et al. Management of lung metastases from colorectal cancer: video-assisted thoracoscopic surgery versus thoracotomy--a case-matched study. Thorac Cardiovasc Surg 2012;60:398-404.

12. Hou Z, Zhang H, Gui L, et al. Video-assisted thoracoscopic surgery versus open resection of lung metastases from colorectal cancer. Int J Clin Exp Med 2015;8:13571-7.

doi: $10.21037 /$ ccts.2020.01.03

Cite this article as: Kirschbaum A, Meyer C, Bartsch D, Mirow N. Video assisted laser resection of lung metastases: a new surgical technique. Curr Chall Thorac Surg 2020;2:17.
13. Guerrini GP, Lo Faso F, Vagliasindi A, et al. The Role of Minimally Invasive Surgery in the Treatment of Lung Metastases. J Invest Surg 2017;30:110-5.

14. Abdelnour-Berchtold E, Perentes JY, Ris HB, et al. Survival and Local Recurrence After Video-Assisted Thoracoscopic Lung Metastasectomy. World J Surg 2016;40:373-9.

15. Graeter TP, Friedel G. Pulmonary Metastases of Colorectal Carcinoma. Zentralbl Chir 2016;141:341-54.

16. Osei-Agyemang T, Palade E, Hadertauer J, et al. Pulmonary metastasectomy: an analysis of technical and oncological outcomes in 301 patients with a focus on laser resection. Zentralbl Chir 2013;138 Suppl $1: \mathrm{S} 45-51$.

17. Meyer C, Bartsch D, Mirow N, et al. Video-Assisted Laser Resection of Lung Metastases-Feasibility of a New Surgical Technique. Thorac Cardiovasc Surg 2017;65:382-6.

18. Pastorino U, Buyse M, Friedel G, et al. Long-term results of lung metastasectomy: prognostic analyses based on 5206 cases. J Thorac Cardiovasc Surg 1997;113:37-49. 